\title{
Amphetamine and pseudoephedrine cross-tolerance measured by c-Fos protein expression in brains of chronically treated rats Nootchanart Ruksee ${ }^{1}$, Walaiporn Tongjaroenbuangam ${ }^{1}$, Stefano O Casalotti*1,2,3 and Piyarat Govitrapong1,4
} \author{
Institute, University College London, 332 gray's Inn Road, London, WC1X 8EE, UK and ${ }^{4}$ Center for Neuroscience and Department of \\ Pharmacology, Faculty of Science, Mahidol University, Rama 6 Road, Bangkok, 10400, Thailand \\ Email: Nootchanart Ruksee - cfncn@mahidol.ac.th; Walaiporn Tongjaroenbuangam - tongjaroen@yahoo.com; \\ Stefano O Casalotti* - s.casalotti@ucl.ac.uk; Piyarat Govitrapong - grpkk@mahidol.ac.th \\ * Corresponding author
}

Address: ${ }^{1}$ Neuro-Behavioral Biology Center, Institute of Science and Technology for, Research and Development, Mahidol University, Salaya, Nakornpathom, 73170, Thailand, 2Faculty of Lifelong Learning, Birkbeck, University of London, Malet Street, London, WC1E 7HX, UK, 3UCL Ear

Published: 6 October 2008

BMC Neuroscience 2008, 9:99 doi:10.1/86/1471-2202-9-99
Received: 8 April 2008

Accepted: 6 October 2008

This article is available from: http://www.biomedcentral.com/147I-2202/9/99

(C) 2008 Ruksee et al; licensee BioMed Central Ltd.

This is an Open Access article distributed under the terms of the Creative Commons Attribution License (http://creativecommons.org/licenses/by/2.0), which permits unrestricted use, distribution, and reproduction in any medium, provided the original work is properly cited.

\begin{abstract}
Background: Pseudoephedrine is a drug commonly prescribed as a nasal decongestant and bronchodilator and is also freely available in cold remedies and medications. The structural and pharmacological similarity of pseudoephedrine to amphetamine has led to evaluation of its psychomotor stimulant properties within the central nervous system. Previous investigations have shown that the acute responses to pseudoephedrine were similar to those of amphetamine and other psychostimulants.

Results: This study examined the effect of chronic administration of pseudoephedrine in rat nucleus accumbens and striatum and identified three further similarities to amphetamine. (i) Chronic exposure to pseudoephedrine reduced the c-Fos response to acute pseudoephedrine treatment suggesting that pseudoephedrine induced tolerance in the animals. (ii) In animals chronically treated with amphetamine or pseudoephedrine the acute c-Fos response to pseudoephedrine and amphetamine was reduced respectively as compared to naïve animals indicating cross-tolerance for the two drugs. (iii)The known involvement of the dopamine system in the response to amphetamine and pseudoephedrine was further confirmed in this study by demonstrating that pseudoephedrine similarly to amphetamine, but with lower potency, inhibited $\left[{ }^{3} \mathrm{H}\right]$ dopamine uptake in synaptosomal preparations.

Conclusion: This work has demonstrated further similarities of the effect of pseudoephedrine to those of amphetamine in brain areas known to be associated with drug addiction. The most significant result presented here is the cross tolerance effect of amphetamine and psudoephedrine. This suggests that both drugs induce similar mechanisms of action in the brain. Further studies are required to establish whether despite its considerable lower potency, pseudoephedrine could pose health and addiction risks in humans similar to that of known psychostimulants.
\end{abstract}




\section{Background}

Pseudoephedrine is a drug commonly prescribed as a nasal decongestant and bronchodilator and is also available in over the counter cold remedy medications. The chemical structure of pseudoephedrine is similar to that of the psychostimulant amphetamine and both are classified as sympathomimetic drugs [1]. Numerous studies have documented the cellular effects of amphetamine which include increased dopamine release, inhibition of dopamine uptake, D1 and D2 dopamine receptor stimulation, CAMP changes, cAMP responsive element binding protein (CREB) activation, immediate-early gene expression and activation of other specific genes such as dynorphin[2].

Within the central nervous system, the nucleus accumbens and the striatum have been identified as important target areas of psychostimulants and opiates whereby repetitive activation of these areas through dopaminergic action is believed to play a major role in the establishment of drug dependence and withdrawal phenomena [3-5].

The expression of immediate-early genes in response to acute administration of potentially addictive drugs is of particular interest with respect to the mechanisms that may trigger dependence. Amphetamine can induce the expression of c-Fos and jun-B and zif:268. This ability to acutely induce immediate-early gene expression in the nucleus accumbens and striatum is now considered to be a general property of psychostimulant drugs [6-9]. The induction of c-fos by psychostimulants is believed to be mediated predominantly via the D1 receptors as demonstrated by the fact that the D1 specific antagonist SCH23390 can strongly inhibit amphetamine and cocaine-induced c-Fos expression and Fos-like immunoreactivity $[6,10]$. However, these findings do not preclude the involvement of other dopamine receptor types in the response to psychostimulants $[8,11]$.

Work in our laboratory employing a drug substitution test indicated that pseudoephedrine elicited, in rats, similar internal cues to amphetamine [12]. Additionally, we demonstrated that pseudoephedrine induced Fos-like immunoreactivity in the nucleus accumbens and striatum regions in a time and concentration-dependent manner with maximal effect at $60 \mathrm{mg} / \mathrm{kg} 2 \mathrm{~h}$ after injection [13]. To further investigate the similarity of amphetamine's and pseudoephedrine's action we have analysed the acute cFos response to psuedoephedrine in rats chronically treated with pseudoephedrine or amphetamine. Additionally, we have compared the effect of pseudoephedrine and amphetamine on dopamine taken up into synaptosomes prepared from rat nucleus accumbens and striatum. The data further indicates that pseudoephedrine operates in a manner similar to amphetamine which may have implications for its over-the-counter use.

\section{Methods}

\section{Animal treatments}

All animal procedures were carried out in compliance with Mahidol University Code of Practice and the National Institutes of Health (USA) Guidelines for treatment of laboratory animals. Male Sprague-Dawley rats (between 200 and $250 \mathrm{~g}$ ) were obtained from the National Animal Center, Mahidol University, Thailand, housed in groups of 6 and maintained on a $12 \mathrm{~h}$ light/ dark cycle with free access to water and food. All animals were handled for at least 1 week before the experiment. In acute treatment, rats were injected intraperitoneally (i.p.) with pseudoephedrine $(40 \mathrm{mg} / \mathrm{kg}$, i.p.) or d-amphetamine ( $3 \mathrm{mg} / \mathrm{kg}$, i.p.) and were killed $1.5 \mathrm{~h}$ after the drug injection. In chronic treatment, rats were injected twice a day ( 8.30 a.m. and 6.30 p.m.) for 8 days with pseudoephedrine (Sigma, Aldrich St. Louis USA) at increasing doses of $25,30,35,40 \mathrm{mg} / \mathrm{kg}$, i.p. on day 1, 2, 3 and $4-8$ respectively. To study cross tolerance with amphetamine, rats were chronically injected twice a day $(8.30$ a.m. and 6.30 p.m.) for 8 days with d-amphetamine at increasing doses of $1,2,2.5,3 \mathrm{mg} / \mathrm{kg}$, i.p. on day $1,2,3$ and $4-8$ respectively. Rats were sacrificed on day $9,1.5 \mathrm{~h}$ after the last injection of either d-pseudoephedrine $(40 \mathrm{mg} / \mathrm{kg}$, i.p.), d-amphetamine ( $3 \mathrm{mg} / \mathrm{kg}$, i.p.) or saline. The final injection on day 9 was carried out at 8:30 a.m. as during the chronic treatment.

\section{Nuclear extract preparation}

Under the stereodissecting microscope, the rat brains were cut coronally at the optic chiasma and $2 \mathrm{~mm}$ more frontally. From this section striatum and nucleus accumbens were manually dissected. The striatum was identified as the striated area below the corpus callosum while the nucleus accumbens as the area surrounding the anterior commisure which is easily identifiable as a small white area. The dissected tissues were used for nuclei isolation as previously described [14]. To obtain sufficient tissue, brain areas from 2-3 similarly treated animals were pooled and homogenized in $2 \mathrm{ml}$ of chilled solution I (0.32 M sucrose, $3 \mathrm{mM} \mathrm{MgCl2,} 1 \mathrm{mM}$ Hepes, $\mathrm{pH}$ 6.8) using a glass Teflon homogenizer. The crude homogenate was transferred to a new centrifuge tube and diluted with $1.2 \mathrm{ml}$ of solution I and $0.44 \mathrm{ml}$ of distilled water. The diluted homogenate was underlaid with $3 \mathrm{ml}$ of solution $\mathrm{I}$, and centrifuged at $1000 \times \mathrm{g}$ for $10 \mathrm{~min}$. The pellet was harvested and resuspended in $5.33 \mathrm{ml}$ of solution II (1.4 $M$ sucrose, $1 \mathrm{mM} \mathrm{MgCl} 2,1 \mathrm{mM}$ Hepes, $\mathrm{pH}$ 6.8), and centrifuged at $50,000 \times \mathrm{g}$ for $10 \mathrm{~min}$ in a fixed angle rotor. The nuclear pellet was harvested and resuspended in 18-20 $\mu \mathrm{l}$ of solution III $(0.25 \mathrm{M}$ sucrose, $1 \mathrm{mM} \mathrm{MgCl} 2,1 \mathrm{mM}$ Hepes, pH 6.8). Protein concentration was determined by 
the method of Lowry [15] where bovine serum albumin was used as a standard.

\section{Western blot}

Western blots were carried out as previously described [13]. Nuclear extract samples were mixed with an equal volume of loading buffer ( $0.1 \mathrm{M}$ Tris ( $\mathrm{pH} 6.8), 4 \%$ sodium dodecyl sulphate (w/v), 20\% glycerol (w/v), 0.2 $M$ of 1,4-Dithiothreitol (DTT) and $0.2 \%$ bromophenol blue (w/v), boiled for $5 \mathrm{~min}$, electrophoresed on $10 \%$ discontinuous sodium dodecyl sulphate acrylamide gel and electroblotted to nitrocellulose membrane. Following transfer, the membrane was briefly washed in transfer buffer, and incubated in blocking solution $(0.02 \mathrm{M}$ Tris, $\mathrm{pH} 7.4,0.15 \mathrm{M} \mathrm{NaCl}, 5 \%$ non-fat dried milk (w/v), 0.05\% Tween $20(\mathrm{v} / \mathrm{v}))$ for $2 \mathrm{~h}$ at room temperature. The membrane was incubated with anti-Fos antibodies (Genosys Ltd., UK.) 1:500 in blocking solution for $1.5 \mathrm{~h}$, washed 4 $\times 7$ min with $50 \mathrm{ml}$ of TBST solution (0.2 M Tris ( $\mathrm{pH} 7.4$ ), $1.5 \mathrm{M} \mathrm{NaCl}, 0.5 \%$ Tween $20(\mathrm{v} / \mathrm{v})$ ) incubated with alkaline phosphatase-conjugated anti-sheep immunoglobulin antibody (Sigma, St. Louis USA) diluted 1:1000 in blocking solution for $1 \mathrm{~h}$ at room temperature and washed first $4 \times 7 \mathrm{~min}$ with $50 \mathrm{ml}$ of TBST solution and finally $7 \mathrm{~min}$ with $50 \mathrm{ml}$ of TBS solution (0.2 M Tris (pH 7.4), $1.5 \mathrm{M}$ $\mathrm{NaCl}$ ). Bands were visualized after addition of Western Blue (Promega, USA) stabilized substrate for alkaline phosphatase. The staining of the specifically labeled 55 KDa c-Fos band was scanned on a flat bed scanner and quantified with the NIH software program.

\section{Synaptosome preparation}

Male Sprague Dawley rats weighing 200-250 g were killed by decapitation and brains were rapidly removed and cooled on ice. The synaptosomes were prepared as previously described [16] with some modifications. The striatum and nucleus accumbens were dissected, weighed and homogenized using a glass teflon homogenizer in 20 volumes of $0.32 \mathrm{M}$ sucrose, $0.12 \mathrm{mM} \mathrm{KH} 2 \mathrm{PO} 4$ and $0.5 \mathrm{mM}$ $\mathrm{Na} 2 \mathrm{HPO} 4(\mathrm{pH} 7.4)$ at $4{ }^{\circ} \mathrm{C}$. Homogenates were centrifuged at $900 \times \mathrm{g}$ for $10 \mathrm{~min}$. The supernatant was further centrifuged at $11,000 \times \mathrm{g}$ for $20 \mathrm{~min}$, The pellet was resuspended in an ice cold Krebs phosphate buffer containing $127.2 \mathrm{mM} \mathrm{NaCl}, 5 \mathrm{mM} \mathrm{KCl}, 1.3 \mathrm{mM} \mathrm{MgSO} 4,1.2 \mathrm{mM}$ KH2PO4, $5 \mathrm{mM} \mathrm{Na} 2 \mathrm{HPO} 4,1.25 \mathrm{mM} \mathrm{CaCl} 2,1 \mathrm{mM}$ EDTA, $0.105 \mathrm{mM}$ ascorbic acid, $1.05 \mu \mathrm{M}$ pargyline and $11.1 \mathrm{mM}$ glucose ( $\mathrm{pH} 7.4)$.

\section{[3H]Dopamine uptake}

Measurement of $\left[{ }^{3} \mathrm{H}\right]$ dopamine uptake into synaptosomes was carried out according to previously published methods $[17,18]$. Test drugs $(50 \mu \mathrm{l}$ of $d$-amphetamine or $d$-pseudoephedrine) followed by $50 \mu \mathrm{l}\left[{ }^{3} \mathrm{H}\right]$ dopamine (final concentration $1 \mathrm{nM}$ ) were added to synaptosomal suspensions $(900 \mu \mathrm{l}$, final protein concentration of stri- atal and nucleus accumbens synaptosomes were $0.44 \pm$ $0.01 \mathrm{mg} / \mathrm{ml}$ and $0.23 \pm 0.01 \mathrm{mg} / \mathrm{ml}$ respectively) to give a final volume of $1 \mathrm{ml}$. The reaction mixture was incubated at $25^{\circ} \mathrm{C}$ for $5 \mathrm{~min}$ in a metabolic shaker water bath. Following incubation, the reaction mixture was rapidly filtered through glass-fiber filter paper (Whatman GF/B) by a vacuum pump and washed twice with $3 \mathrm{ml}$ of Krebs phosphate buffer. The synaptosomes containing radioactive dopamine trapped on filter paper were counted by liquid scintillation spectrometry (Beckman LS 1801) in 5 $\mathrm{ml}$ of TritonX-100/Toluene base fluor (1:3) scintillation fluid. The active accumulation of $\left[{ }^{3} \mathrm{H}\right]$ dopamine was determined as the difference of the radioactivity accumulated in the synaptosomes in the presence and absence of $1 \mu \mathrm{M}$ nomifensine.

The inhibition was determined as percent of controls and the $\mathrm{IC}_{50}$ values were calculated from at least four separate experiments, each conducted in duplicates, and the $95 \%$ confidence limits were calculated by non-linear regression analysis from the approximately linear part of the log concentration response curves.

\section{Statistical analysis}

All c-Fos expression values are optical density measurements (arbitrary units) and are represented as mean \pm S.E.M normalized to $100 \%$ of control. A one-way analysis of variance (ANOVA) was used. Post-hoc tests were performed using the Tukey test to compare significance between the individual groups. The significance was taken when $p$-values were less than 0.05 .

\section{Results}

Effect of chronic pseudoephedrine treatment on the c-Fos acute response to pseudoephedrine in nucleus accumbens and striatum

The relative c-Fos response in nucleus accumbens and striatum was measured by densitometry of immunostained bands in a Western blot assay. Pseudoephedrine $(40 \mathrm{mg} / \mathrm{kg}$, i.p.) induced an acute increase in c-Fos expression in the nucleus accumbens and striatum as compared with saline-treated rats (Fig. 1). The peak c-Fos response was reached at 1.5 hours after treatment. It was maintained for up to 30 further minutes and was just above control at 3 hours after treatment (results not shown). The bands represent the $55 \mathrm{KDa}$ c-Fos peptide.

To determine effect of pseudoephedrine chronic treatment, rats were chronically injected with either saline or pseudoephedrine twice a day for 8 days and sacrificed 1.5 $\mathrm{h}$ after a final psuedoephedrine injection on day 9 . Chronic exposure to pseudoephedrine significantly reduced $(p<0.05)$ the acute c-Fos response to pseudoephedrine in the nucleus accumbens and striatum as 


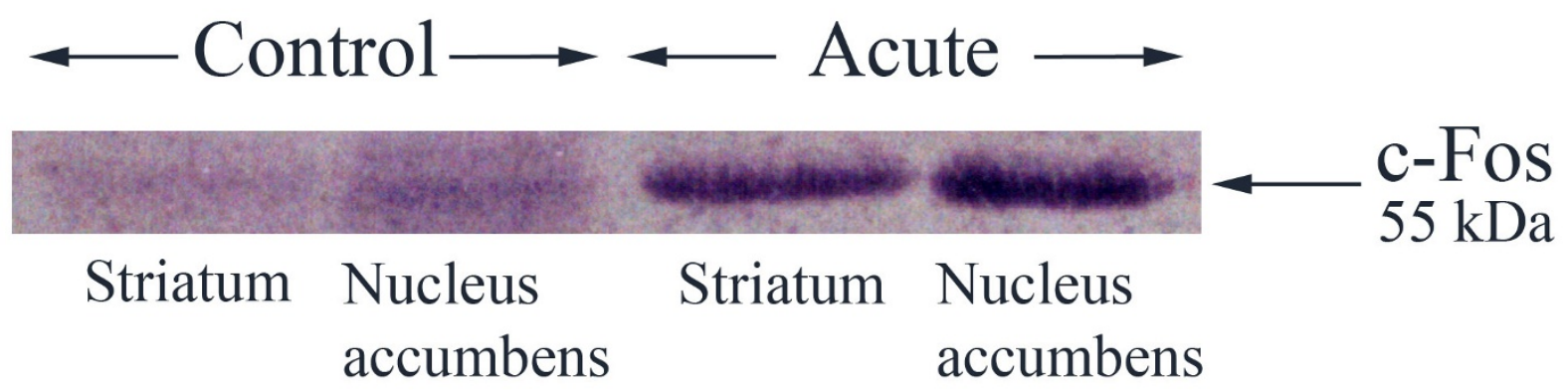

Figure I

Pseudoephedrine induced c-Fos expression. Western blot analysis was used to measure the acute pseudoephedrine (40 $\mathrm{mg} / \mathrm{kg}$, i.p) induced c-Fos expression in striatum and nucleus accumbens. c-Fos protein was detected I.5 h after saline and pseudoephedrine injection.

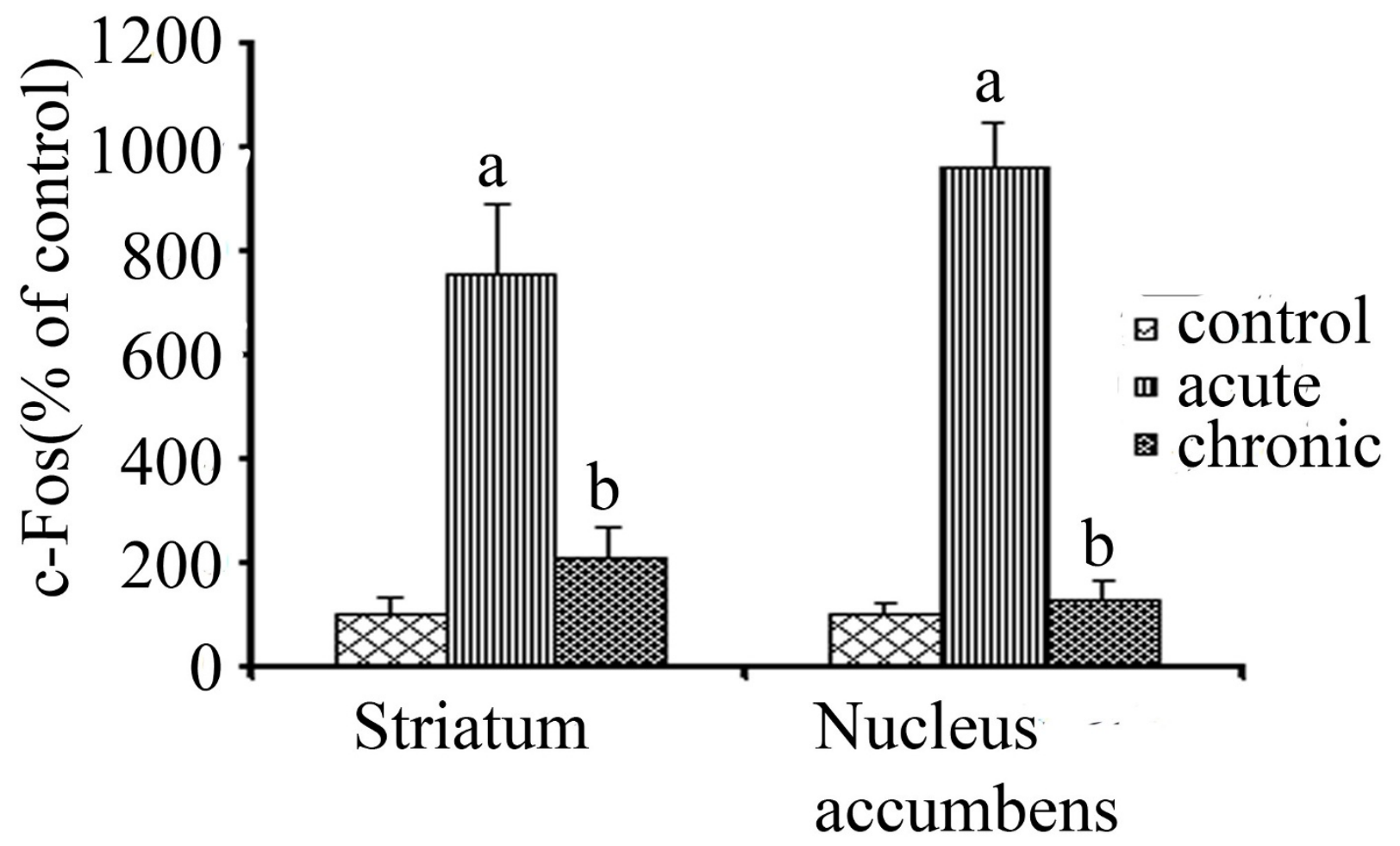

Figure 2

Effect of chronic drug treatment on acute c-Fos response. Western blot analysis was used to measure the acute pseudoephedrine induced c-Fos expression in striatum $(n=4)$ and nucleus accumbens $(n=3)$ of rats chronically treated with pseudoephedrine (8 day treatment of pseudoephedrine twice a day with an increasing dose at 25, 30, 35, $40 \mathrm{mg} / \mathrm{kg}$ i.p., on day I, 2, 3 and 4-8 respectively, rats were killed $1.5 \mathrm{~h}$ after $40 \mathrm{mg} / \mathrm{kg}$, i.p pseudoephedrine injection on day 9). The data (quantification of bands from western blots) is expressed as percentage of c-Fos value of control animals injected with saline. (A value of I00\% indicates no difference from control) Values are mean \pm S.E.M. 'a' indicates significantly different from control and chronic; ' $b$ ' indicates significantly different from acute with $p<0.05$. 
compared with animals chronically treated with saline (Fig. 2).

\section{Cross tolerance between pseudoephedrine and amphetamine}

The following experiments were designed to test whether chronic treatment with pseudoephedrine also affected the acute response to other psychostimulants. Rats were chronically injected with either saline, amphetamine or psuedoephedrine for 8 days as described, and on day 9 they received a final injection of either pseudoephedrine or amphetamine respectively (i.e. pseudoephedrine treated rats received a final injection of amphetamine and vice versa) and sacrificed $1.5 \mathrm{~h}$ after the last injection. Measurements of c-Fos expression in the nucleus accumbens and striatum indicated that chronic treatment with either amphetamine or pseudoephedrine caused a reduction $(p<0.005)$ in the acute response to both drugs (Fig. 3) indicating that pseudoephedrine and amphetamine have cross tolerance and may use a common pathway to induce the expression of c-Fos protein.

\section{The effects of $d$-pseudoephedrine on $\left[{ }^{3} \mathrm{H}\right]$ dopamine uptake}

In order to investigate the mechanism of action of pseudoephedrine and to compare it to that of amphetamine, the effect of pseudoephedrine and amphetamine on $\left[{ }^{3} \mathrm{H}\right]$ dopamine uptake was assayed in synaptosomal preparations from rat brain areas. Both amphetamine and pseudoephedrine inhibited the uptake of $\left[{ }^{3} \mathrm{H}\right]$ dopamine into nucleus accumbens and striatal synaptosomes, with amphetamine being more potent than pseudoephedrine (Fig. 4). The amphetamine and pseudoephedrine curves were parallel to each other with the curve for pseudoephedrine inhibition of $\left[{ }^{3} \mathrm{H}\right]$ dopamine uptake shifted to the right. The $\mathrm{IC}_{50}$ values for amphetamine and pseudoephedrine inhibition reported here (see legend Fig. 4) indicate that amphetamine was 156 and 180 times more potent than pseudoephedrine at inhibiting $\left[{ }^{3} \mathrm{H}\right]$ dopamine uptake into striatal and nucleus accumbens synaptosomes, respectively.

\section{Discussion}

Chronic injection of pseudoephedrine resulted in desensitisation of the acute pseudoephedrine induced c-Fos induction in the striatum and nucleus accumbens. It has previously been shown that chronic treatment with cocaine and amphetamine reduces the immediate-earlygene expression response to these drugs in specific brain areas [19-21]. Pseudoephedrine effects on c- Fos expression is thus similar to that of other psychostimulants both at the acute and chronic level. The c-Fos response to psychomotor stimulant drugs appears to be a direct response to the drug rather than to a general drug-related altered state. For example other studies have shown that there are no significant changes in c-Fos expression following withdrawal from chronic treatment of psychostimulants (22).

To further test the hypothesis that amphetamine and pseudoephedrine work through similar mechanisms, cross tolerance tests were carried out. The results indicate that in amphetamine and in pseudoephedrine chronically treated rats the c-Fos response in the striatum and nucleus accumbens following a final injection with pseudoephedrine and amphetamine respectively, was lower than in naïve animals. This result is consistent with our previous findings that pseudoephedrine has similar effects and mechanisms of action as amphetamine in terms of c-Fos expression [13] and internal behavioral cues [12]. In this work we have also analysed another reported effect of psychostimulants namely inhibition of $\left[{ }^{3} \mathrm{H}\right]$ dopamine uptake and report that both amphetamine and pseudoephedrine inhibit $\left[{ }^{3} \mathrm{H}\right]$ dopamine uptake. The role of dopamine in pseudoephedrine induced c-Fos response is further corroborated by the effect of the D1 receptor antagonist SCH23390 which as previously described [13] inhibited acute response to pseudoephedrine (results not shown).

\section{Conclusion}

Our studies thus indicate that pseudoephedrine, notwithstanding the higher doses required, acts in manner indistinguishable from amphetamine. This may have sociological and medical implications as pseudoephedrine is a legal over-the-counter drug. Doses of pseudoephedrine in over-the-counter formulations vary between 60-120 mg/pill and a large amount of pills would need to be ingested to equate the doses injected into rats in this study. However, it is unknown whether the efficacy of the pseudoephedrine in humans is different from rats. An additional potential risk of pseudoephedrine is reinstatement of drug seeking behaviour in individuals that have overcome previous addiction to psychostimulants. It would be useful to determine whether pseudoephedrine could induce a reinstatement of drug seeking behaviour in rats that had first been chronically treated with amphetamine and that had then been allowed to extinguish their amphetamine seeking behaviour. Particular attention would need to be paid to the genetic background of the animals as it has been shown to affect relapse behaviour [23]. The data here reported and the additional approach described above would inform further studies in human subjects aimed at determining the potency of pseudoephedrine in humans to identify what doses may constitute a health, addiction or relapse risk.

\section{Authors' contributions}

NR carried out all the animal treatment and western blot experiments and drafted the manuscript. WT carried out 


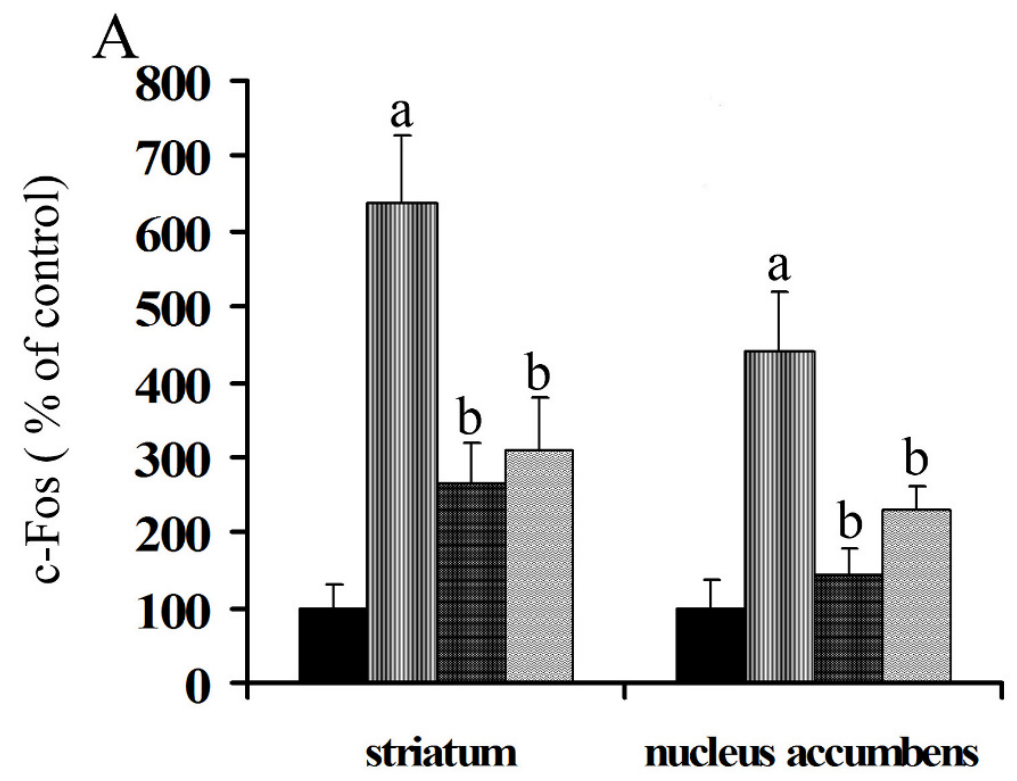

Chronic saline + acute saline (control)

血 Chronic saline + acute amphetamine

眾 Chronic amphetamine + acute amphetamine

图 Chronic pseudoephedrine + acute amphetamine

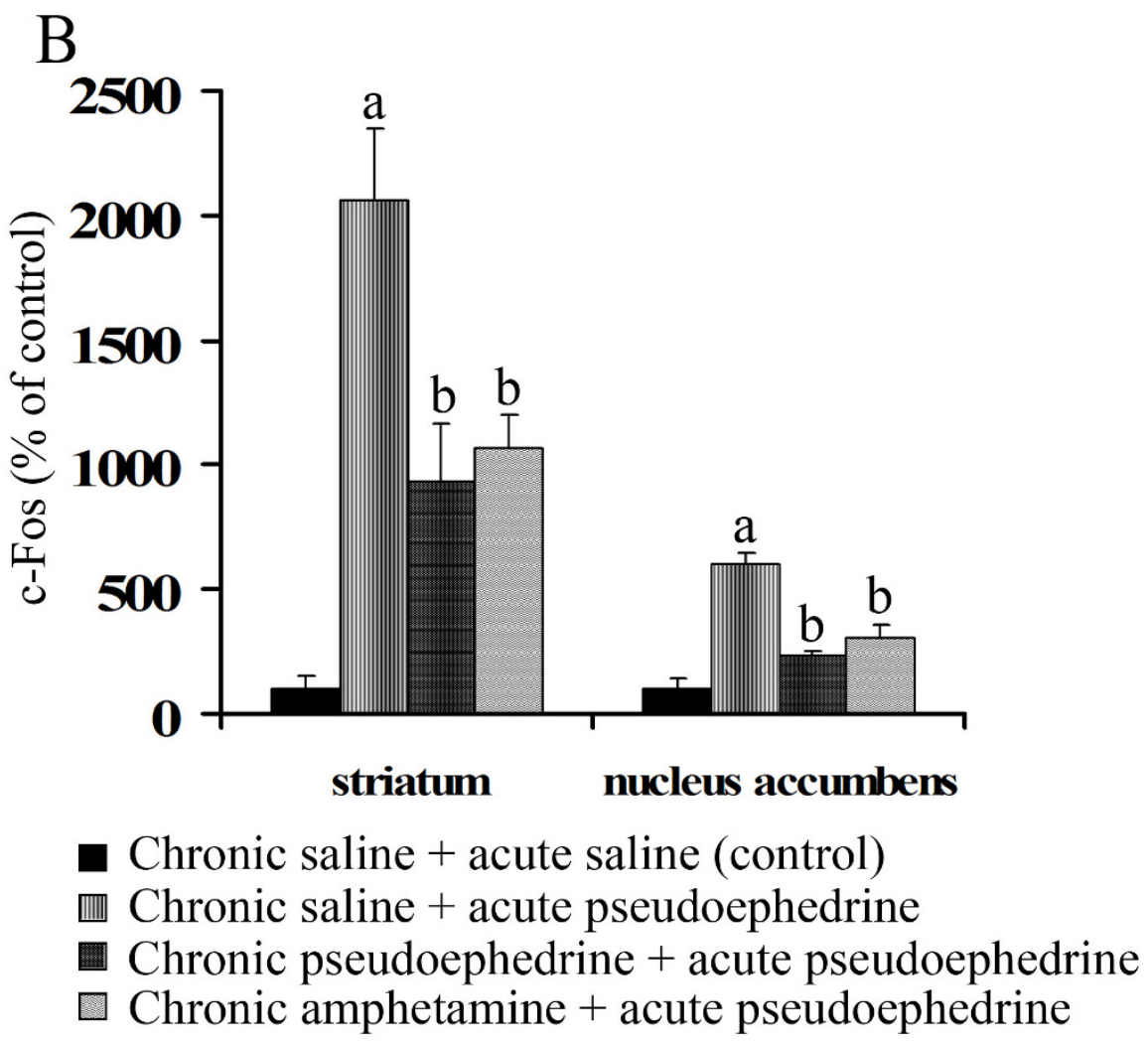

Figure 3 (see legend on next page) 
Figure 3 (see previous page)

Cross tolerance between amphetamine and pseudoephedrine. Western blot analysis was used to measure the level of cross-tolerance between pseudoephedrine and amphetamine to drug induced c-Fos expression in striatum ( $n=3$ ) and nucleus accumbens $(n=3)$ in chronically treated rats. A: acute response to amphetamine in rats chronically treated with saline, amphetamine and pseudoephedrine ( 8 day treatment of drug twice a day with an increasing dose schedule; rats were killed I.5 $\mathrm{h}$ after $40 \mathrm{mg} / \mathrm{kg}$, i.p pseudoephedrine injection). There was no significant difference in the acute response to amphetamine between rats chronically treated with amphetamine or pseudoephedrine. B: acute response to pseudoephedrine in rats chronically treated with saline, pseudoephedrine and amphetamine ( 8 day treatment of drug twice a day with an increasing dose schedule, rats were killed $1.5 \mathrm{~h}$ after $40 \mathrm{mg} / \mathrm{kg}$, i.p pseudoephedrine injection). There was no significant difference in the acute response to pseudoephedrine between rats treated with amphetamine or pseudoephedrine. The data are expressed as percentage of c-Fos value of control animals injected with saline. Values are mean \pm S.E.M. a indicates significantly different from control and chronic; $b$ indicates significantly different from acute, $p<0.05$.
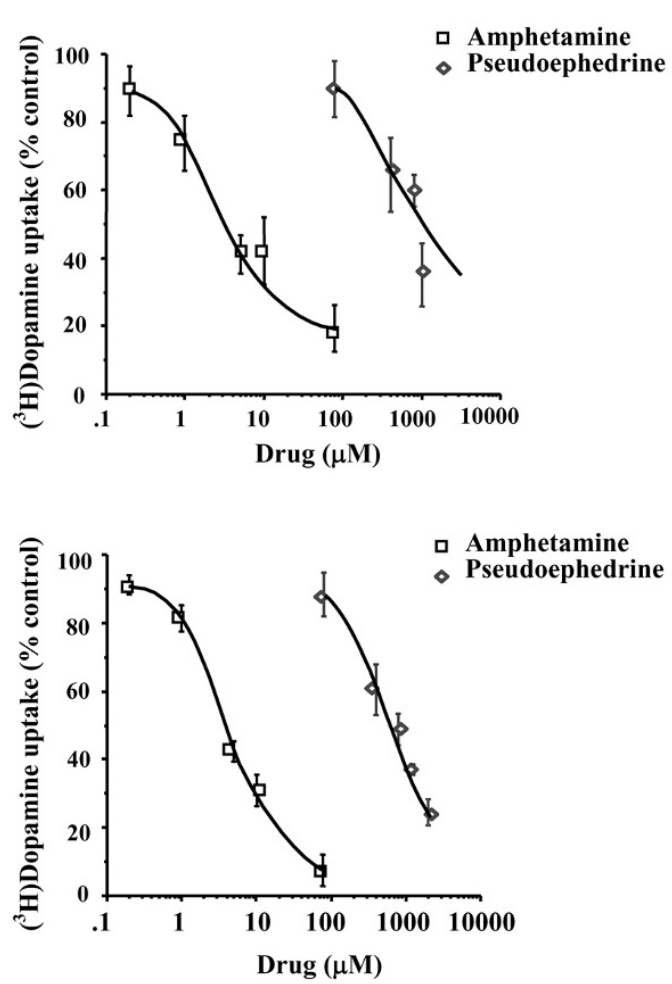

Figure 4

$\left[{ }^{3} \mathrm{H}\right]$ dopamine uptake in rat brain synaptosomes.

Effect of $d$-amphetamine and $d$-pseudoephedrine on

$\left[{ }^{3} \mathrm{H}\right]$ dopamine uptake in rat striatal $(\mathrm{n}=8)$ and nucleus accumbens $(n=4)$ synaptosomes. $I C_{50}$ is defined as the concentration of drug producing a 50 percent inhibition in I $\mathrm{nM}$ $\left[{ }^{3} \mathrm{H}\right]$ dopamine uptake. Values represent uptake as percentage of control. $I C_{50}$ values are mean \pm S.E.M. from duplicate samples in each independent experiment. The $I_{50}$ values of amphetamine in inhibiting $\left[{ }^{3} \mathrm{H}\right]$ dopamine uptake in striatum and nucleus accumbens are $4.28 \pm 0.47$ and $2.95 \pm 0.42 \mu \mathrm{M}$, respectively, and of $d$-pseudoephedrine in inhibiting $\left[{ }^{3} \mathrm{H}\right]$ dopamine uptake in striatum and nucleus accumbens are $667 \pm 126$ and $530 \pm 61 \mu \mathrm{M}$, respectively. the synaptosome experiments and contributed to the draft of the manuscript. SOC devised the experiment plan for the western blots and finalized the manuscript. PG devised the experiment plan for the synaptosome work, critically reviewed the final manuscript preparation and provided overall coordination for the project.

\section{Acknowledgements}

This study was partly supported by a TRF-Senior Research Scholar Fellowship from the Thailand Research Fund and a Mahidol University Research Grant to PG.

\section{References}

I. Hoffman BB, Lefkowitz RJ: The Pharmacological Basis of Therapeutics Goodman and Gilmans's 9th edition. Edited by: Hardman JG, Limbird LE, Molinoff PB, Ruddon RW, Gilman AG. McGraw-Hill International Edition; 1996: 199-248.

2. McCann UD, Ricuarte GA: Amphetamine neurotoxicity: accomplishments and remaining challenges. Neurosci Biobehav Rev 2004, 27:821-826.

3. Hyman SE: Addiction to cocaine and amphetamine. Neuron 1996, 16:901-904.

4. Koob GF: Drug addiction: the yin and yang of hedonichomeostasis. Neuron 1996, 16:893-896.

5. Nestler EJ: Under siege: the brain on opiates. Neuron 1996 16:897-900.

6. Graybiel AM, Moratalla R, Robertson HA: Amphetamine and cocaine induce drug-specific activation of the c-fos gene in striosome-matrix compartments and limbic subdivision of the striatum. Proc Natl Acad Sci USA 1990, 87:69|2-6916.

7. Cole AJ, Bhat RV, Patt C, Worley PF, Baraban JM: DI dopamine receptor activation of multiple transcription factors genes in rat striatum. I Neurochem 1992, 58:1420-1426.

8. Nguyen TV, Kosofsky BE, Birnbaum R, Cohen BM, Hyman SE: Differential expression of c-fos and Zif 268 in rat striatum after haloperidol, clozapine and amphetamine. Proc Natl Acad Sci USA 1992, 89:4270-4274.

9. Conversi D, Orsini C, Cabib S: Distinct patterns of Fos expression induced by systemic amphetamine in the striatal complex of C57BL/6JICo and DBA/2JICo inbred strains of mice. Brain Res 2004, 1025:59-66.

10. Young ST, Porrino LJ, ladarola MJ: Cocaine induces striatal cFosimmunoreactive proteins via dopaminergic DI receptors. Proc Natl Acad Sci 1991, 88: 1 291-1 295.

II. Wang JQ, McGinty J: Differential effects of DI and D2 dopamine receptor antagonist on acute amphetamine-or methamphetamine induced upregulation of zif:268 mRNA expression in rat forebrain. J Neurochem 1995, 65:2706-27I5.

12. Tongjaroenbuangam W, Meksuriyen D, Govitrapong P, Kotchabhakdi $\mathrm{N}$, Baldwin BA: Drug discrimination analysis of pseudoephedrine in rats. Pharmacol Biochem Behav 1998, 59(2):505-510. 
13. Kumarnsit E, Harnyuttanakorn P, Meksuriyen D, Govitrapong P, Baldwin BA, Kotchabhakdi N, Casalotti SO: Pseudoephedrine, a sympathomimetic agent, induces Fos-like immunoreactivity in rat nucleus accumbens and striatum. Neuropharmacology 1999, 38: $138 \mid-1387$

14. Tata JR: Isolation of nuclei from liver and other tissue. Methods Enzymol I974, 3 I A:253-262.

I5. Lowry OH, Rosebrough MS, Farr AL, Randall RJ: Protein measurement with the folin phenol reagent. J Biol Chem 195I, 193(1):265-275.

16. Wheeler DD, Edwards AM, Ondo JG: Dopamine uptake in five structures of the brain: comparison of rate, sodium dependence and sensitivity to cocaine. Neuropharmacology 1993, 32(5):50I-508.

17. Horn AS, Cuello AC, Miller RJ: Dopamine in the mesolimbic system of the rat brain: endogenous levels and the effects of drugs on the uptake mechanism and stimulation of adenylate cyclase activity. I Neurochem 1974, 22:265-270.

18. Hendley ED, Snyder SH, Fauley JJ, LAPidus JB: Stereoelectivity of catecholamine uptake by brain synaptosomes: studies with ephedrine, methylphenidate and phenyl-2-piperidyl carbinol. J Pharmacol Exp Ther 1972, 183:103-116.

19. Hope BT, Kosofsky B, Hyman SE, Nestler EJ: Regulation of immediate early gene expression and AP-I binding in the rat nucleus accumbens by chronic cocaine. Proc Natl Acad Sci USA 1992, 89:5764-5768.

20. Couceyro P, Pollock KM, Drews K, Douglass J: Cocaine differentially Regulates activator protein-I mRNA levels and DNAbinding complexes in the rat striatum and cerebellum. Mol Pharmacol 1994, 46(4):667-676.

21. Turgeon SM, Pollack AE, Fink JS: Enhanced CREB phosphorylation and changes in c-Fos and FRA expression in striatum accompany amphetamine sensitization. Brain Res 1997, 749(I):120-126.

22. Moratalla R, Bulent Eilbol, Mario Vallejo, Ann M Graybiel: Networklevel changes in expression of inducible Fos - Jun proteins in the striatum during chronic cocaine treatment and withdrawal. Neuron 1996, I7:147-I56.

23. $\mathrm{Xi}$, , Kruzich PJ: Black agouti $(\mathrm{ACl})$ rats show greater drug- and cue-induced reinstatement of methamphetamine-seeking behavior than Fischer 344 and Lewis rats. Pharmacol Biochem Behav 2007, 87:90-97.

Publish with Bio Med Central and every scientist can read your work free of charge

"BioMed Central will be the most significant development for disseminating the results of biomedical research in our lifetime. "

Sir Paul Nurse, Cancer Research UK

Your research papers will be:

- available free of charge to the entire biomedical community

- peer reviewed and published immediately upon acceptance

- cited in PubMed and archived on PubMed Central

- yours - you keep the copyright
BioMedcentral 